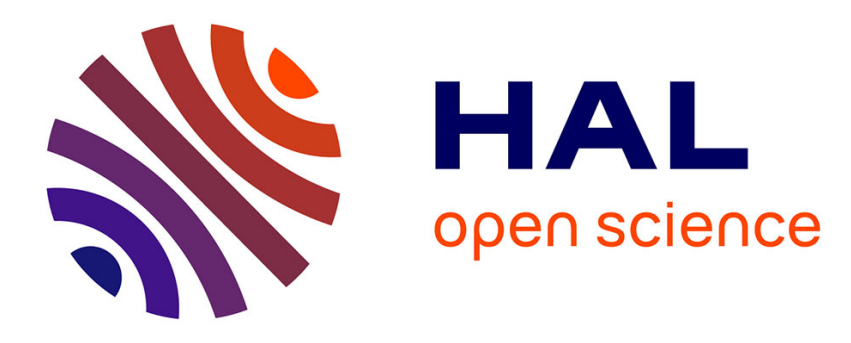

\title{
From Models of Hemoproteins to Self-Assembled Molecular Wires
}

Christophe Kahlfuss, Jennifer A. Wytko, Jean Weiss

\section{To cite this version:}

Christophe Kahlfuss, Jennifer A. Wytko, Jean Weiss. From Models of Hemoproteins to Self-Assembled Molecular Wires. ChemPlusChem, 2017, 82 (4), pp.584-594. 10.1002/cplu.201600557 . hal-03386569

\section{HAL Id: hal-03386569 \\ https://hal.science/hal-03386569}

Submitted on 19 Oct 2021

HAL is a multi-disciplinary open access archive for the deposit and dissemination of scientific research documents, whether they are published or not. The documents may come from teaching and research institutions in France or abroad, or from public or private research centers.
L'archive ouverte pluridisciplinaire HAL, est destinée au dépôt et à la diffusion de documents scientifiques de niveau recherche, publiés ou non, émanant des établissements d'enseignement et de recherche français ou étrangers, des laboratoires publics ou privés. 


\section{From models of hemoproteins}

\section{to self-assembled molecular}

wires

Christophe Kahlfuss, ${ }^{[a]}$ Jennifer A. Wytko, ${ }^{[a]}$ Jean

Weiss ${ }^{\star[a]}$ 
Abstract: In Nature, the various properties of tetrapyrrolic macrocycles are mostly due to their proteic environment and result from an evolutionary process difficult to reproduce in the lifetime of a synthetic chemist. Thus, the task of synthetic chemists attempting to reproduce the biological role of porphyrin architectures performing functions from catalysis to light harvesting is significantly complicated. This account describes how a phenanthroline-strapped porphyrin architecture initially designed to afford new hemoprotein models led, over the last two decades, to the preparation of highly linear self-assembled nano-objects inspired by light-harvesting architectures. The approach summarized in the next pages mimics, in a very modest way, the polyvalence of tetrapyrrolic macrocycles in Nature.

\section{Introduction}

Porphyrins, or more generally tetrapyrrolic macrocycles, are the archetype of the multipurpose chemical object in Nature. Owing to their multiple biological functions, porphyrins have been called "Pigments of Life"[1] and have survived eons of evolution as demonstrated by their presence in various sediments ${ }^{[2]}$ or meteorites. ${ }^{[3]}$ Although evolution differentiated hemes from chlorophylls and bacteriochlorophylls (Figure 1), porphyrin derivatives can fulfil many tasks without major changes in their macrocyclic or tetrapyrrolic character.

These macrocycles are highly stable planar 18-electron aromatic structures and can contain up to $22 \pi$ electrons in their neutral form. Porphyrins are highly colored and can accommodate a wide range of metals that dictate the electroactive ( $\mathrm{Co}, \mathrm{Mn}, \mathrm{Fe})$ or photoactive $(\mathrm{Zn}, \mathrm{Mg})$ nature of the chromophore. For decades, synthetic organic chemists have extensively functionalized the porphyrin ring either at the eight $\beta$ pyrrolic or the four meso $(5,10,15$ and 20) positions (Figure 1) to reproduce or mimic biological processes. After a brief conceptual introduction of the classical designs of hemoprotein models, this account will show how a particular strapped porphyrin, initially designed as a bioinorganic model for cytochrome $c$ oxidase, further led to the efficient self-assembly of chromophores.

\begin{tabular}{ll}
\hline [a] & Dr. Christophe Kahlfuss \\
Dr. Jennifer A. Wytko \\
Dr. Jean Weiss \\
\hline UMR 7177 CNRS-Université de Strasbourg \\
1, rue Blaise Pascal \\
F-67000 Strasbourg \\
France \\
E-mail: jweiss@unistra.fr
\end{tabular}

Jean Weiss received his Ph.D.. in 1986 under the supervision of Dr. Jean-Pierre Sauvage at the Université Louis Pasteur de Strasbourg. After post-doctoral fellowships with Dr. D. J. Cram at UCLA and Prof. Dr. H. A. Staab at the MPI in Heidelberg as an Alexander von Humboldt fellow, he joined Prof. Maurice Gross at the CNRS in Strasbourg. Since 1998 his independent research has focused on hemoprotein models, redox molecular switches, self-assembly, and molecular electronics.

\section{The Holy Grail of natural model sophistication}

The fundamental differences in the metal-dependent behavior of porphyrin derivatives are not sufficient to explain the tremendous variety of their precise functions in natural processes. This diversity and the finely tuned reactivity of metallo-porphyrins are only possible because of the high degree of sophistication of the biological matrix that surrounds the "active" porphyrin unit and controls the location, orientation and access to the tetrapyrrolic moiety. Haemoglobin is a typical example of the control of position and access in a hemoprotein. The location of the four hemes (iron porphyrin) results from the presence of a hydrophobic pocket and the orientation of each heme is tuned by the positioning of the hydrophilic $\mathrm{COOH}$ residues (two out of eight circled in black in Figure 2a) at the periphery of the globular protein structure ${ }^{[4,5]}$ Once in the pocket, the heme's position is locked by the coordination of a histidine residue to the iron(II) (circled in black in Figure $2 b$ ). The face of the heme in close proximity to its environment is defined as the proximal side. Access of any exogenic ligand to the other side of the heme is controlled by a distant histidine residue and this open side of the heme is denominated "distal". In general, the two faces of all hemoproteins are distinguished; consequently, reproducing the distal/proximal control in synthetic models has been a major challenge in the design of bioinorganic models.

In the vegetal and bacterial photosynthetic processes, the location of the photoactive tetrapyrrole is directed and locked by interactions of the chlorophyll or bacteriochlorophyll either with itself ${ }^{[6]}$ or with $\alpha$ or $\beta$ helical polypeptides (Figure $2 c$ ). ${ }^{[7]}$ When the biological matrix is not represented, as in Figure $2 \mathrm{~d}$, the regular arrangement of the porphyrin derivatives can be clearly seen

\section{Distal/Proximal control in porphyrin synthesis}

A widely acknowledged breakthrough in the field of hemoprotein models was the discovery of the picket-fenced porphyrin and the report of its oxygen binding properties in 1975. ${ }^{[8]}$ Within a few years, various types of superstructured porphyrins bearing 


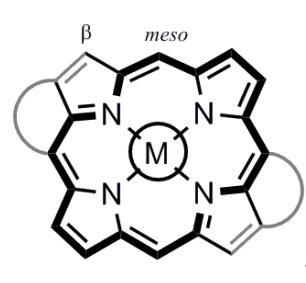

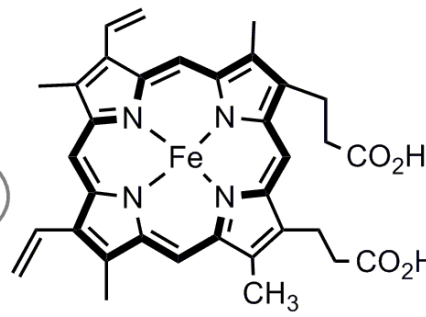

Protoporphyrin IX

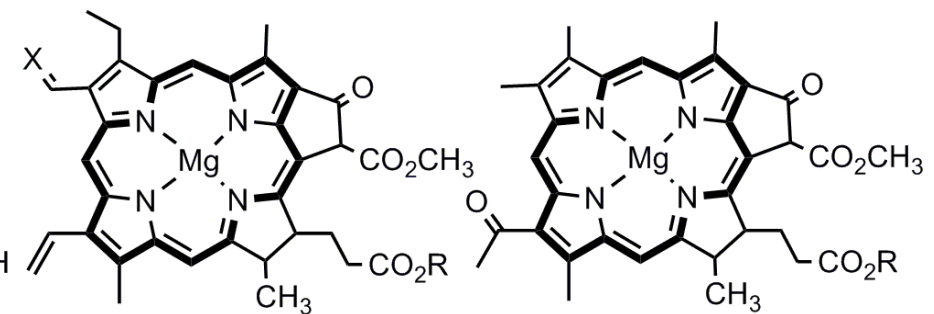

Chlorophyll

a: $\mathrm{X}=\mathrm{CH}_{2}$

$\mathrm{b}: \mathrm{X}=\mathrm{O}$

$R=$ Phytyl
Bacteriochlorophyll a $\mathrm{R}=$ Phytyl or Geranyl

Figure 1. The porphyrin macrocycle (left). The aromaticity pathway is shown in bold. The gray lines and arcs represent possible structural alterations observed in Nature in the structures of protoporphyrin IX, chlorophylls and bacteriochlorophylls.

straps,${ }^{[9]}$ caps $^{[10]}$ handles across ${ }^{[11]}$ or on the side ${ }^{[12]}$ not only succeeded in differentiating both faces of a generic mesotetraphenyl-porphyrin structure, but also provided information on the control of coordination geometries of metalloporphyrins. Despite significant efforts and the unlimited imagination of synthetic chemists, most strategies utilized to introduce structural components that differentiated the proximal and distal sides resulted in rather tedious syntheses and low yields of the targeted model, thus preventing further refinement of the binding site, aside from metallation with iron. ${ }^{[13]}$

In the early 90 s, our interest in rigid structures and metal cooperativity in redox or catalytic process was sparked by geometric hypotheses made for the bimetallic enzyme

a)

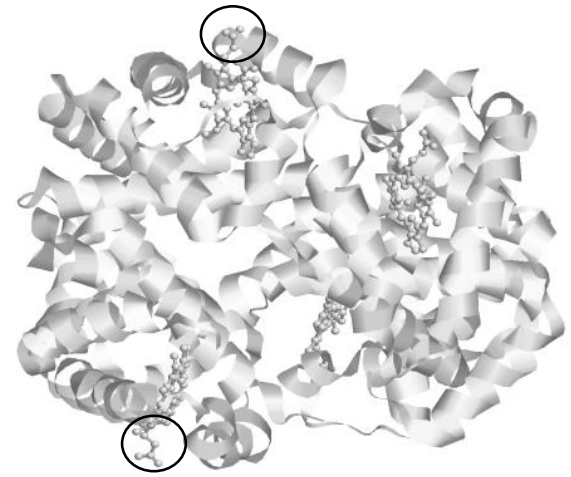

b)

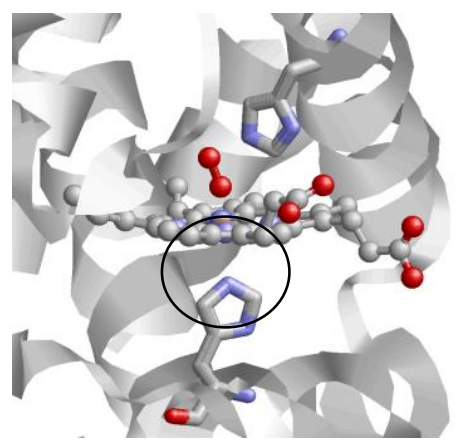

cytochrome $c$ oxidase. ${ }^{[14]}$ In its reduced state $\left(\mathrm{Fe}^{11}-\mathrm{Cu}^{\prime}\right)$, this enzyme binds $\mathrm{O}_{2}$ to generate a $\mu$-peroxo bridged ( $\mathrm{Fe}$ "ll- $-\mathrm{Cu}$ "I) species that is further reduced into $\mathrm{H}_{2} \mathrm{O}$ by successive electron transfers from the neighbouring tyrosine and cytochrome c. $^{[15 a, b]}$

Although this enzyme's structure (Figure 3) was only obtained in $1995,{ }^{[15 c]}$ the design of our model in 1992 was determined from spectroscopic data ${ }^{[14]}$ suggesting rather precise geometric features within the structure. A highly rigid strapped porphyrin was thus targeted, combining a 1,10-phenanthroline (phen) binding site, hindered at the 2 and 9 positions to bind and stabilise $\mathrm{Cu}^{\prime}$ rather than $\mathrm{Cu}^{\prime \prime}$, with a porphyrin for the preparation of heme analogues.

c)

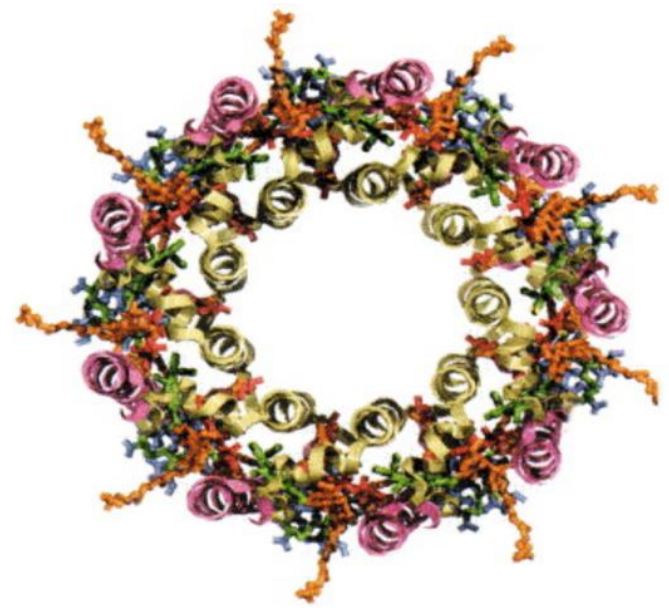

d)

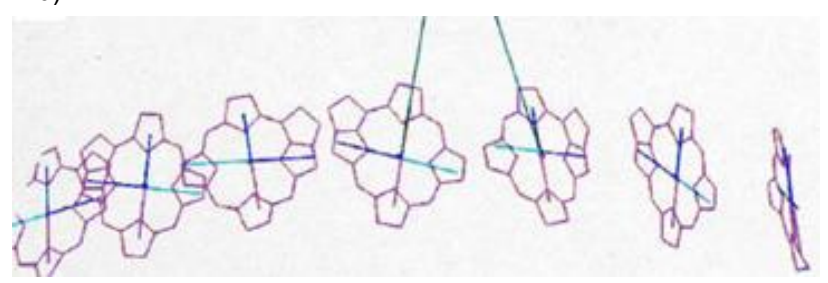

Figure 2. a) X-ray diffraction structure of the oxygenated T-state of haemoglobin (1GZX from ref. [6]); b) Detail of the oxygen binding site; c) Complete view of the LH2 complex in Rhodopseudomonas Viridis and d) Detail of the geometric arrangement of Bacteriochlorophyll a units (from ref. [7]). 


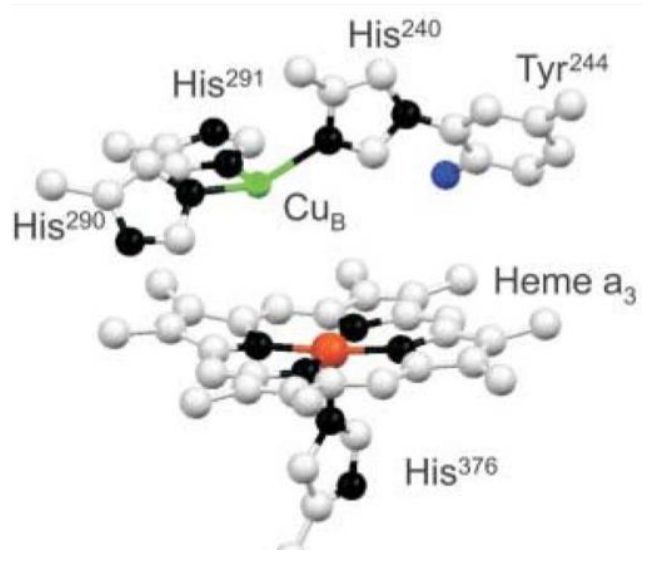

Figure 3. X-ray diffraction structure at $2.3 \AA$ resolution of the oxidized cytochrome $c$ oxidase active site from bovine heart (ref. [15]). Geometric features: distance $\left(\mathrm{Fe}_{\mathrm{a} 3}-\mathrm{Cu}\right) \sim 4.5 \AA$, offset $\sim 0.3 \AA$. (ref. [15]). intermediate ${ }^{[17]}$ and the cyclisation is extremely efficient $(>60 \%)^{[18]}$ considering that the formation of the 1 and 2 requires the connection of six reaction centres. ${ }^{[19,20]}$ By modifying the methoxy substituents of 2 to long alkyl ethers (3) (Figure 4), highly soluble species were obtained. ${ }^{[20]}$

\section{Pendant coordinating side arms: completing the hemoprotein models}

In terms of developing heme protein models, the phen strap provides a predefined distal binding site that can be considered as invariable, thus our initial aim was to introduce small variations using the anchoring points of the porphyrin periphery. Substituents were introduced at the two unsubstituted meso positions of porphyrins $\mathbf{1}$ and $\mathbf{2}$ by Suzuki couplings with boronic acid derivatives of resorcinyl or phenol ethers to generate ligands 4-11 (Figure 4).

Over the last decade, the properties of zinc, iron, zinc-

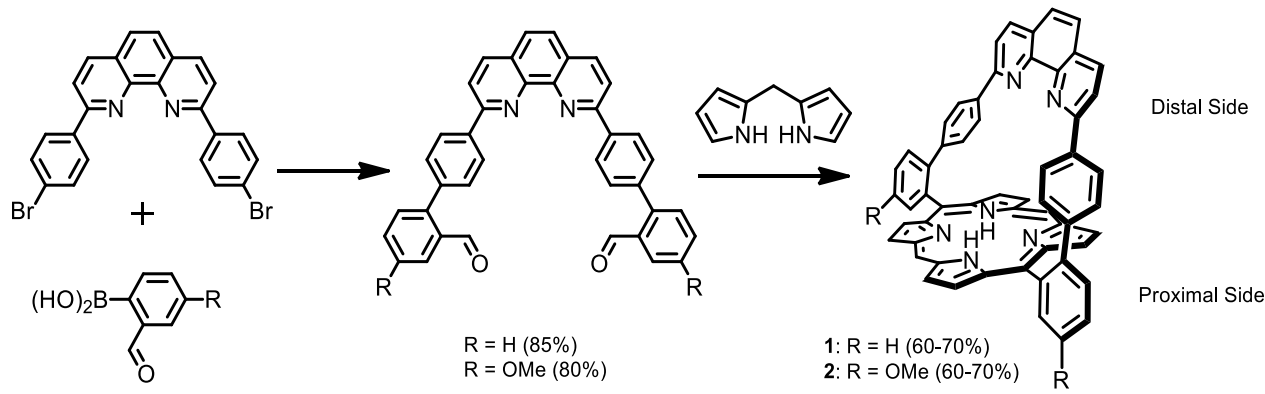

Scheme 1. Synthesis of the strapped porphyrin framework

Inspired by Manka and Lawrence's efficient synthesis of 5,10-diarylporphyrins, ${ }^{[16]}$ the synthesis of the phen-strapped porphyrin was planned around an approach utilizing the cyclisation of a dialdehyde strap (Scheme 1) with unsubstituted dipyrrylmethane. The dialdehyde can be easily prepared on large scale via a bis-2,9-(p-bromophenyl)-1,10-phenanthroline copper and iron-copper complexes of 4-11 have been studied by NMR, X-ray, electrochemistry and vibrational spectroscopies. These ligands illustrate one main advantage of the phenstrapped structure, namely that the peripheral variations of 4 to 11 do not affect the characteristic features of the porphyrin and the phen binding sites. Changes in the efficiency of $\mathrm{O}_{2}$ tetra-
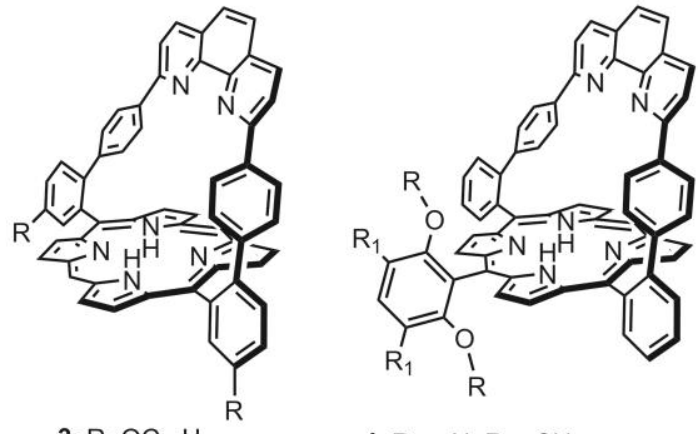

3: $\mathrm{R}=\mathrm{OC}_{18} \mathrm{H}_{37}$

$$
\begin{aligned}
& \text { 4: } \mathrm{R}_{1}=\mathrm{H} ; \mathrm{R}=\mathrm{CH}_{3} \\
& \text { 5: } \mathrm{R}_{1}=\mathrm{H} ; \mathrm{R}=\mathrm{H} \\
& \text { 6: } \mathrm{R}_{1}=\mathrm{H} ; \mathrm{R}=\left(\mathrm{CH}_{2}\right)_{3} \mathrm{Br} \\
& \text { 7: } \mathrm{R}_{1}=\mathrm{H} ; \mathrm{R}=\left(\mathrm{CH}_{2}\right)_{3} \mathrm{~N}-\mathrm{Im} \\
& \text { 8: } \mathrm{R}_{1}=\mathrm{C} 7 \mathrm{H}_{15} ; \mathrm{R}=\left(\mathrm{CH}_{3}\right)_{3} m-\mathrm{Py} \\
& \text { 9: } \mathrm{R}_{1}=\text { allyl; } \mathrm{R}=\left(\mathrm{CH}_{3}\right)_{3} m-\mathrm{Py}
\end{aligned}
$$

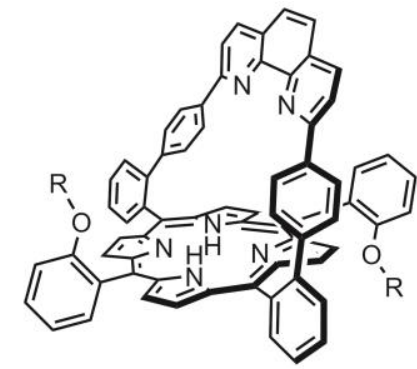

10: $\mathrm{R}=\left(\mathrm{CH}_{2}\right)_{4} m$-Pic<smiles>Cn1ccnc1</smiles>

$\mathrm{N}-\mathrm{Im}$

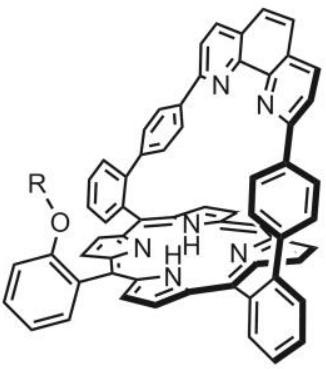

11: $\mathrm{R}=\left(\mathrm{CH}_{2}\right)_{4} m$-Pic<smiles>Cc1cccnc1</smiles>

$m-\mathrm{Pyr}$

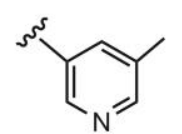

$m$-Pic

Figure 4. Bio-inspired heme protein models built on the phen-strapped porphyrin motif. 

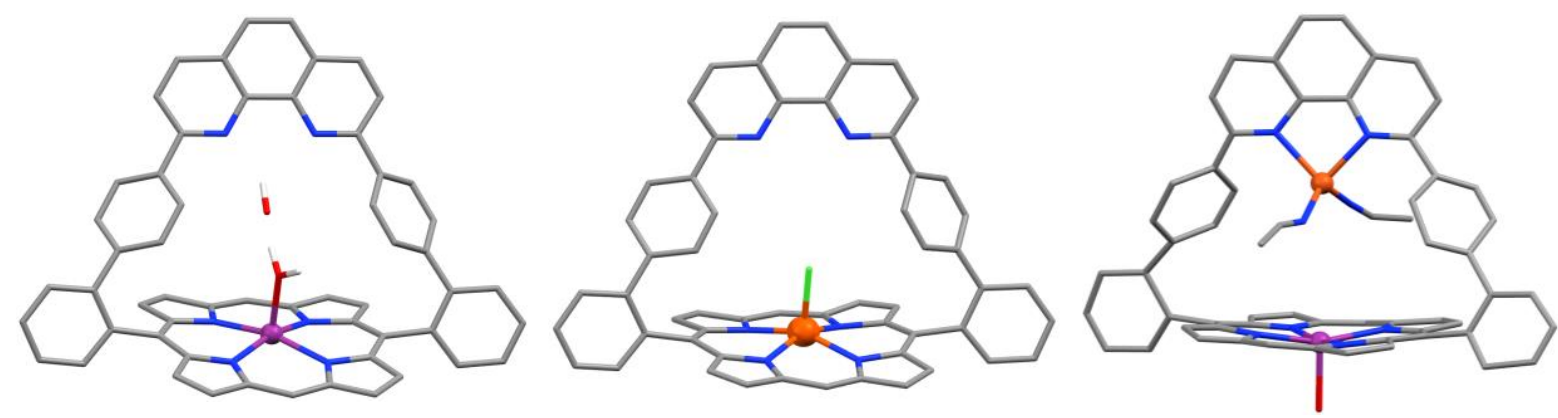

Figure 5. Metallic and hetero bi-metallic complexes in the phen-strapped porphyrin. Left: zinc(II) bis aquo complex; Center: iron(III) chloride complex; Right: zinc(II) copper(I) complex. Relevant distances are discussed in the text.

electronic reduction mostly depend on the basicity and steric bulk of the ancillary ligands. In 4-9, the motion of the ancillary ligands is necessarily concerted, whereas in $\mathbf{1 0}$, the ancillary ligands move independently.

Generally, zinc(II) is employed as an accurate diamagnetic model for iron(II) porphyrins because the electronic configuration of zinc(II) allows the binding of an apical fifth ligand, yielding a square pyramidal geometry analogous to that of high spin $(\mathrm{S}=2)$ pentacoordinated iron(II). The ability of these strappedporphyrins to coordinate various metals was confirmed by the $\mathrm{X}$ ray structures in Figure 5 . The distance from the metal to the phen's nitrogen atoms depends on the out-of-plane location of the metal within the porphyrin core. This distance was estimated at $6.5 \AA$ in $1 \mathrm{Zn}\left(\mathrm{H}_{2} \mathrm{O}\right)_{2}{ }^{[21]}$ and $\mathbf{1} \mathrm{FeCl}^{[22]}$ and $6.7 \AA$ in $1 \mathrm{Zn}\left(\mathrm{CH}_{3} \mathrm{OH}\right) \mathrm{Cu}\left(\mathrm{CH}_{3} \mathrm{CN}\right)_{2},{ }^{[22]}$ where the zinc atom sits $0.23 \AA$ out-of-plane on the face opposite the strap due to $\mathrm{MeOH}$ coordination. In the latter bimetallic structure, the metal-metal distance is $5.0 \AA$. Thus, the ligand's architecture allows small structural variations to modulate the metal-metal distance in the strap within a range that is compatible with $\mathrm{Fe}-\mathrm{Cu}$ distances in different states of an enzyme.

Although the phen-strapped porphyrin and its metal complexes are keen to form single crystals, only one structure 9Zn of a model possessing ancillary ligands was determined by

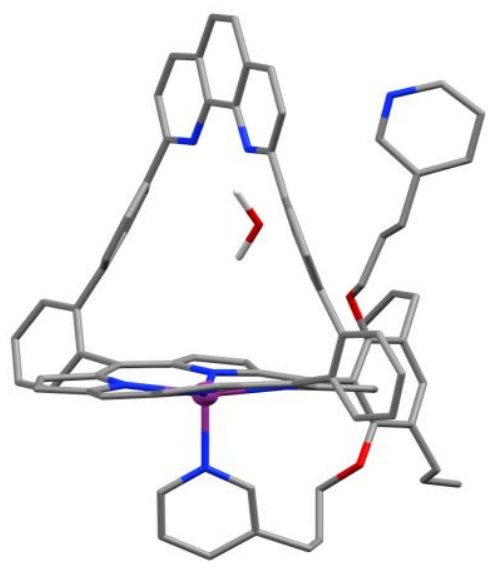

Figure 6. X-Ray diffraction structure of $9 \mathrm{Zn}$. Contrary to $1 \mathrm{Zn}\left(\mathrm{H}_{2} \mathrm{O}\right)_{2}$, the $\mathrm{H}_{2} \mathrm{O}$ molecule is not bound to the scaffold.
X-ray diffraction. The structure in Figure 6 shows that the open face mimics the proximal face of the heme. Coordination of the pyridine on the face opposite to the strap was confirmed by $2 \mathrm{D}$ ${ }^{1} \mathrm{H} \mathrm{NMR} .{ }^{[23]}$ Switching the metal from zinc(II) to iron(III) precludes the use of the NMR, but provides a probe for EPR, which is very informative regarding the coordination state of iron(III). In the absence of additional restraints, the presence of the strap is insufficient to fully control the proximal/distal binding. EPR studies of $7 \mathrm{FeCl}$ and $9 \mathrm{FeCl}$ showed a pentacoordinated high spin iron(III) state that is consistent with decoordination of the chloride ${ }^{[24]}$ and an imidazole coordination geometry in $7 \mathrm{FeCl}$ similar to that of $\mathbf{9 Z n}$. Whereas an exogenic ligand is able to enter the phen pocket to bind on the distal side, the coordination of a sixth pendant ligand induces some geometrical constraints in the framework. ${ }^{[25]}$

In general, the behaviour of the models in the ferrous state was difficult to anticipate, aside from the high reactivity of the parent structures lacking built-in axial bases. [22]Erreur ! Signet non défini. In models $\mathbf{8 F e - 1 0 F e , ~ w h e n ~ t h e ~ f e r r o u s ~ s t a t e ~ i s ~ g e n e r a t e d ~ i n ~ t h e ~}$ absence of copper(I) in the phen strap, the pyridine moiety is able to enter the strap and act as a sixth ligand for the iron(II), significantly lowering its affinity for oxygen to render the iron(II) complex air stable. To prevent coordination of the distal base in the iron(II) complexes, copper(I) needs to be inserted prior to chemical or electrochemical generation of the iron(II) species.

The efficiency of each model for the tetraelectronic reduction of oxygen was assessed by electrochemistry under physiological $\mathrm{pH}$ conditions (oxygen-saturated phosphate buffer). ${ }^{[26,27]}$ An analysis focusing on the nature of the axial bases clearly shows that the electron rich character of the axial base is of utmost importance and that the presence of copper has no influence on the reduction potential for iron-bound oxygen. The largest overpotential versus the uncatalyzed reduction of oxygen is observed for $\mathrm{N}$-alkyl imidazole as axial base, regardless of the built-in character of the base. When a simple strapped-porphyrin [3Fe] ${ }^{+}$or $[3 \mathrm{FeCu}]^{2+}$ is employed with an excess of $\mathrm{N}$-methylimidazole, the potential of the catalytic activity is as anodic as that of built-in axial bases derived from imidazole but the number of electrons exchanged is significantly lower $\left(3,3.5\right.$ and 4 electrons for $[3 \mathrm{Fe}]^{+},[3 \mathrm{FeCu}]^{2+}$ and $[7 \mathrm{Fe}]^{+}$ respectively) probably due to the partial decoordination of the imidazole ligand on the open (proximal) side of the porphyrin and the formation of $\mu$-oxo side products. 
The distal coordination of imidazole inside the phen pocket in the case of iron(II) derivatives is also detrimental to the ligation of oxygen and thus to the efficiency of the catalysis. Although it is admitted that the presence of copper in the enzyme provides a relay for rapid electron transfer, for phenstrapped porphyrins, it is obvious that copper binding also preserves the exclusive access to the distal cavity to small exogenic ligands. This selectivity was established for both $[7 \mathrm{Fe}]^{+[26]}$ and $[9 \mathrm{Fe}]^{+[28]}$ Whereas the binding of copper in [9Fe] ${ }^{+}$ is necessary to observe oxygen binding, the use of sterically hindered picolinic pendant side arms renders [11Fe] ${ }^{+}$highly sensitive to traces of oxygen irrespective of the presence of copper in the phen strap. Model [9Fe] ${ }^{+}$also reproduced the enzyme's behaviour in the presence of $\mathrm{CO}$ and reversibly form a

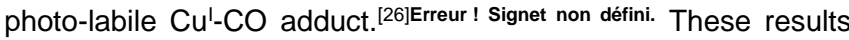
have shown that a similar binding site containing the same porphyrin unit and a predefined distal side can behave quite differently despite their large resemblance. The control of the reactivity in these heme protein models strongly depends on how the nature of the axial base(s) influences the reduction potential for the four-electron reduction of oxygen, the steric hindrance and geometric constraints and, more importantly, the ligation of copper in the vicinity of the distal site. The latter ultimately controls the efficiency of the oxygen binding. Thus, the phen pocket itself has intrinsic host-guest properties which have also been explored with the zinc derivatives of phen-strapped porphyrins.

\section{Metallic structures and inclusion complexes}

The essence of the design of strapped porphyrins has always concerned the control of the fifth coordination site to mimic the proximal coordination in hemoproteins because steric requirements generally orient the binding of an axial ligand to the open face of the host. ${ }^{[28]}$ This assumption has proven valid in all cases that involved no interactions other than the coordination of the metal core. The strapped-porphyrin $1 \mathrm{Zn}$ is just one example of a receptor that combines several features of a typical porphyrin host: an electron poor central metal core, a hydrophobic pocket defined by two lateral $p$-phenylene rings, and two $\mathrm{H}$-bond accepting sites provided by the apical nitrogen atoms of the phen.

According to these general principles, ${ }^{1} \mathrm{H}$ NMR and UVvisible studies of the zinc porphyrin $\mathbf{1 Z n}$ have converged to show that pyridine or $\mathrm{N}$-alkyl imidazoles are exclusively bound at the open face of $\mathbf{1 Z n} .{ }^{[29]}$ However, due to the presence of the $\mathrm{H}$ bond accepting imine functions of the strap, the receptor exhibits highly selective recognition properties of $\mathrm{N}$-unsusbstituted imidazoles, binding these ligands within the phen pocket. ${ }^{1} \mathrm{H}$ NMR observations are sufficient to determine the coordination site of an axial base.

Several X-ray structures (Figure 7) confirmed the selective recognition of $\mathrm{N}$-unsubstituted imidazoles within the phen pocket. ${ }^{[30]}$ The relaxed structure of $1 \mathrm{Zn}$ cimidazole shows the perfect alignment of the imidazole guest with the meso-meso direction of the macrocycle. The distorted structures of the inclusion compounds of a bis(xylyl) porphyrin derivative $12 \mathrm{Zn}$ with methyl-benzimidazole or 2-phenyl-imidazole illustrate the strength of the distal binding pocket and the flexibility of the phen strap.

Detailed binding studies and kinetic analysis performed on all receptors showed that the steric hindrance in the receptor ultimately governs the associative or dissociative character of the imidazole binding. ${ }^{[31]}$ The presence of bulky susbstituents decreases the rate of the recognition process, whereas the inertness or resistance to dissociation is controlled by the development of additional stabilizing interactions, namely $\mathrm{CH}-\pi$ interactions, $\mathrm{H}$-bond formation, hydrophobic effects and aromatic stacking.

\section{Axial binding as an assembly tool}

The reversible formation of coordination bonds is essential to the reactivity of metalloenzymes, from the selection and recognition of the substrate to its conversion and release. As mentioned in the introduction, the formation of coordination bonds between hydroxyl groups and magnesium is also essential to the proper structuring of pigments in light-harvesting antennae. The latter provides a typical example of a selfcorrecting self-assembled structure. For decades, self-assembly

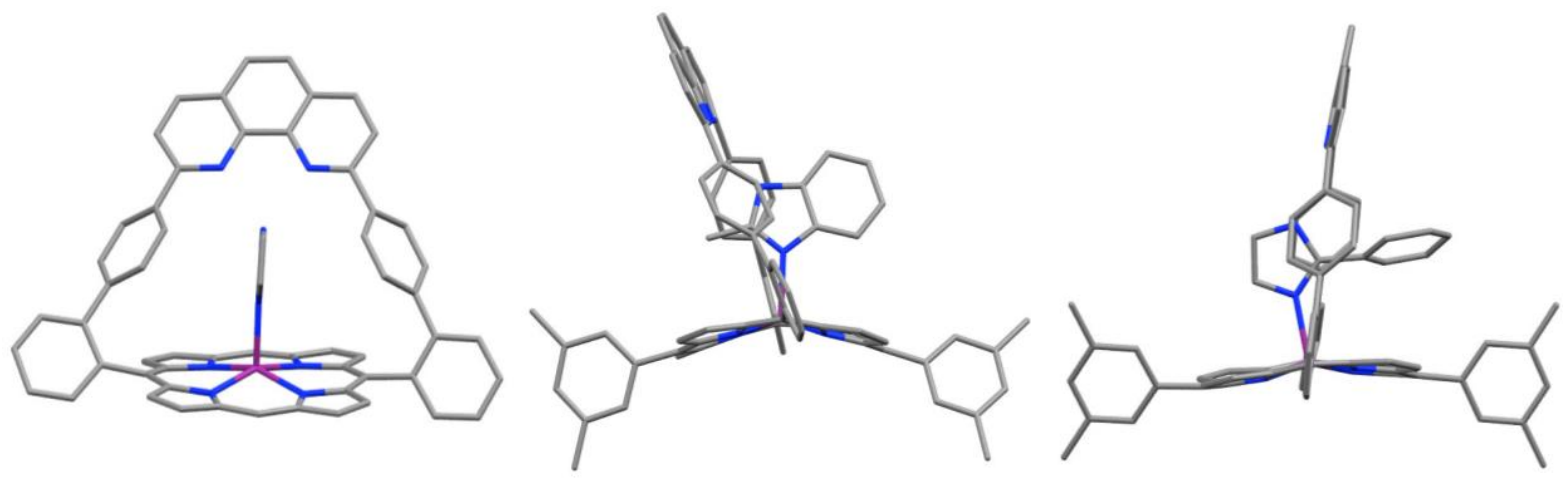

Figure 7. Solid state structures of inclusion complexes of $\mathbf{1 Z n}$ and $\mathbf{1 2 Z n}$ obtained by $\mathrm{X}$-ray diffraction:

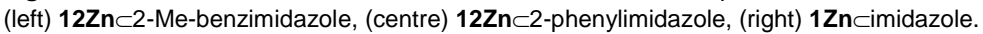




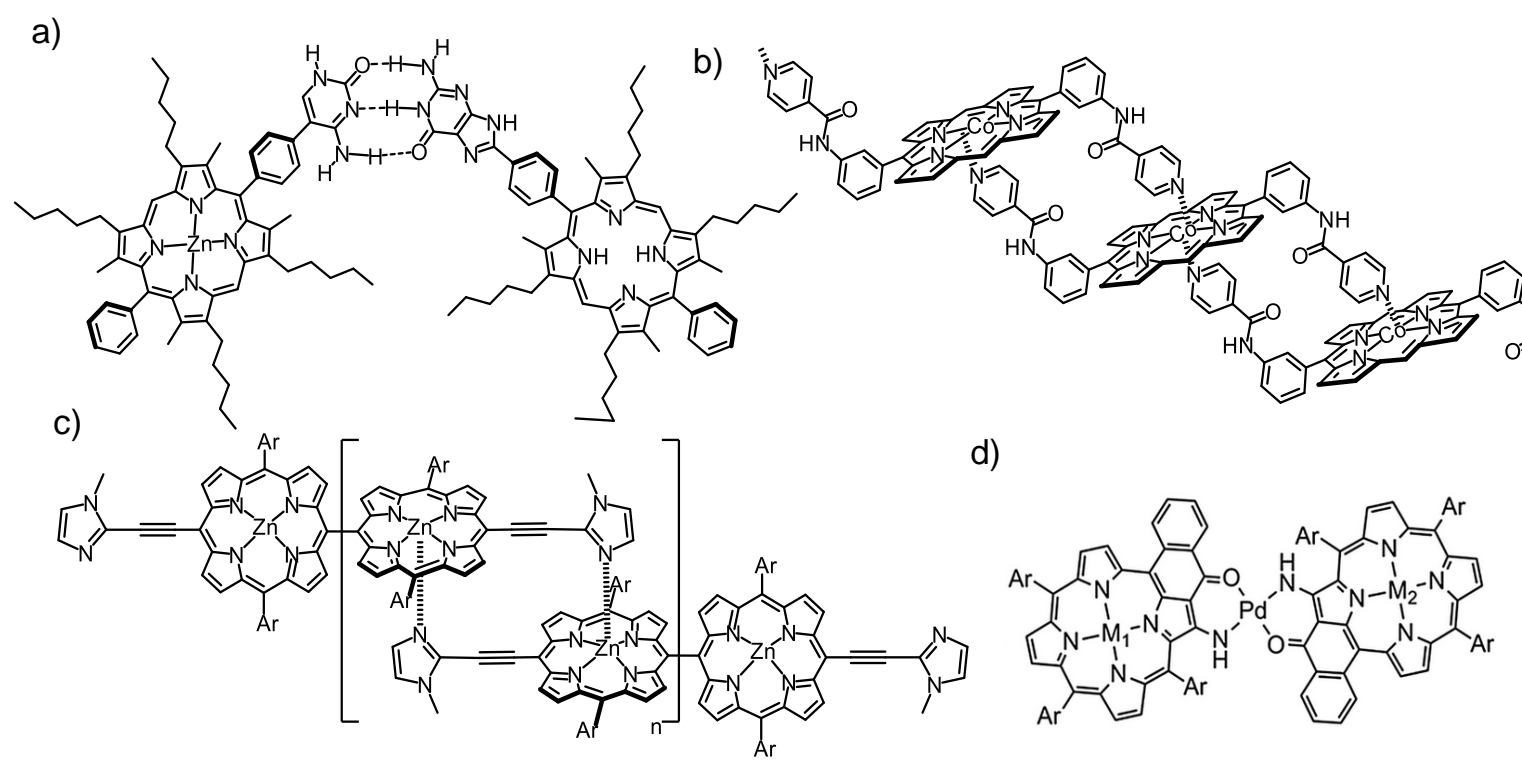

Figure 8. Self-assembled multiporphyrins using weak interactions such as (a) DNA type H-bonding, (b-c) axial metal binding and (d) peripheral metal-ligand coordination.

of multi-porphyrinic architectures through weak interactions has been a research field so active that it cannot be exhaustively covered here. Thus, only a few pioneering examples from the literature will be used to illustrate and better understand our contribution to the field of linear self-assembled porphyrin wires.

In the general case of linear self-assembly, weak interactions are combined to introduce specific constraints in the process. The geometric requirements of each type of interaction, e.g. H-bond, coordination, $\mathrm{CH}-\pi$ or dipole-dipole, are then repeated or associated to enhance the specificity of the assembling. Several reviews concerning self-assembly of porphyrins are available. ${ }^{[32]}$

In Figure 8a, multiple $\mathrm{H}$-bond formation between donor (D)-donor-acceptor (A) (or DDA) and AAD substituents grafted on porphyrin rings afforded photochemical dyads. ${ }^{[33]}$ The compounds in Figure 8b-c illustrate the versatility of axial metal binding, depending on the hexa ${ }^{[34]}$ or pentacoordinated ${ }^{[35]}$ nature of the central metallic core. These assemblies also highlight how directionality is imposed by iterative coordination of self- complementary motifs. The last example (Figure 8d) demonstrates the use of exogenic metal binding sites to prepare dyads, in which case the choice of the bridging metal can modulate the electronic communication. The steric and electronic requirements of the building block determine their orientation within the dyad. ${ }^{[36]}$ Considering the extremely precise positioning of imidazoles in the phen pocket of $1 \mathbf{Z n}$, this selective recognition process was further studied as an assembly tool.

\subsection{Optimized design of self-assembled dyads and triads}

In a first development, the formation of self-assembled dyads (Figure 9) was explored to optimize the communication between the energy donor $\mathbf{1 Z n}$ and a free base porphyrin acceptor (14-16) as a function of the length of the connector. Shorter linkers led to more efficient energy transfer. ${ }^{[37,38]}$ Excitation energy transfer (EET) studies using time resolved lifetime measurements established that the EET proceeds

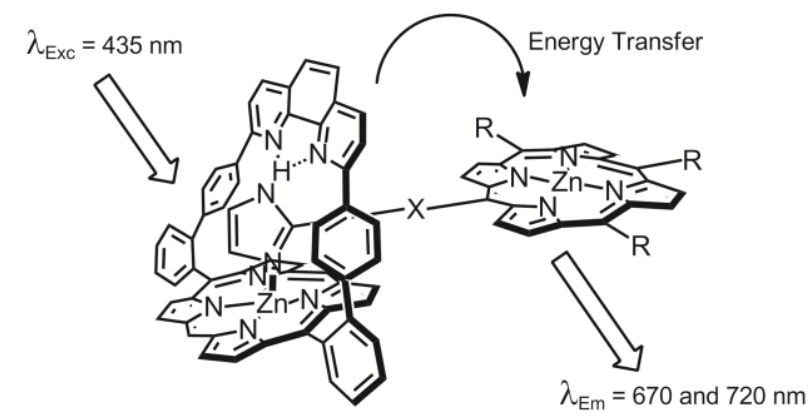

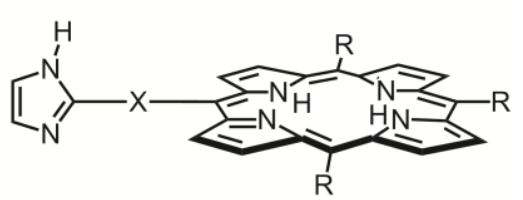

$14: X=\equiv$

$15: x=\equiv$

16: $x=\equiv$

Figure 9. Schematic representation of a self-assembled photochemical dyad using three different free base energy acceptors bearing various spacers. 


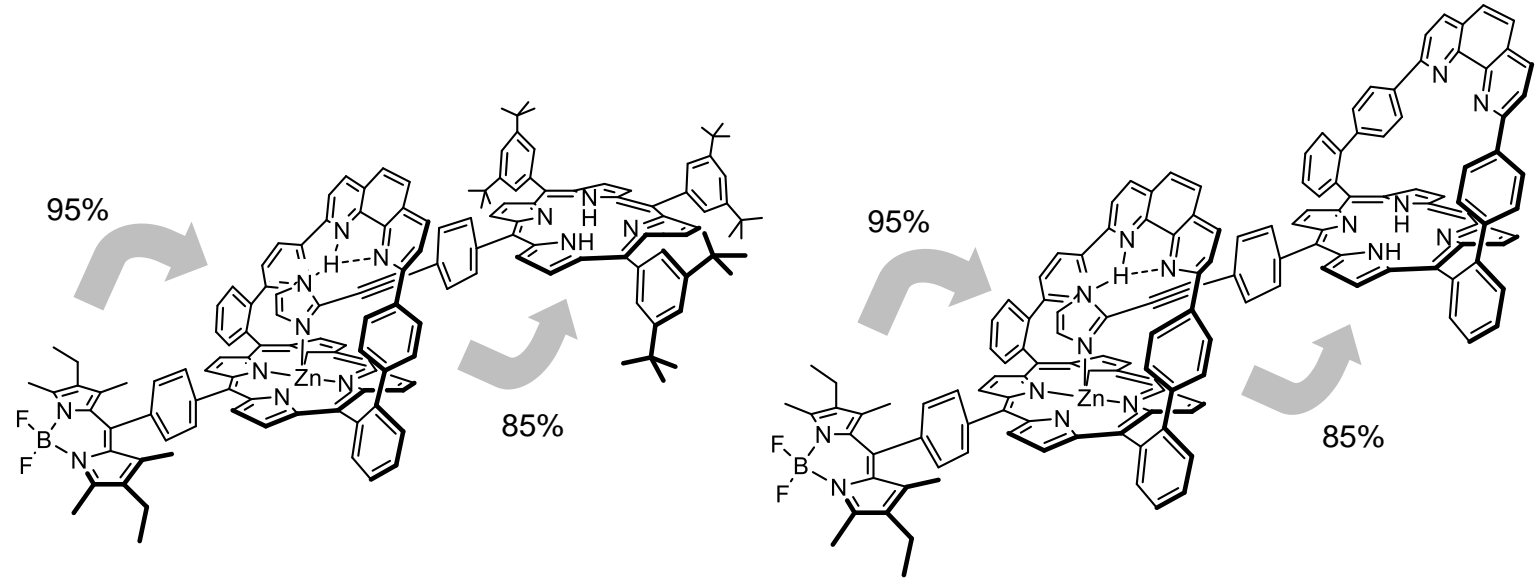

Figure 10. Two photonic triads assembled via selective imidazole binding. Excitation energy transfer yields measured by fluorescence quenching (static measurements).

exclusively via resonant energy transfer or Förster mechanism. ${ }^{[38]}$ These studies also showed that the apparent incomplete transfer observed by static fluorescence quenching experiments was due to back energy transfer from the acceptor to the initial donor, due to partial overlap of the emission of the excited acceptor and the lowest energy absorption band of the

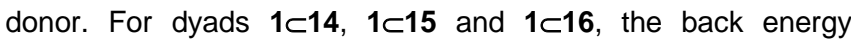
transfer rates of respectively $4 \times 10^{9} \mathrm{~s}^{-1}, 0.6 \times 10^{9} \mathrm{~s}^{-1}$ and $0.1 \mathrm{x}$ $10^{9} \mathrm{~s}^{-1}$ provided, at that time, some rare quantitative data on back energy transfer process.

The observation of back energy transfer illustrates one of the drawbacks of multi-porhyrins scaffolds, namely the absence of a distinct excitation wavelength due to overlapping portions of the absorption spectra of free base and zinc porphyrins. This inconvenience was addressed at the early stages of the design of porphyrin wires by Lindsey and Wagner in a pioneering article on a linear covalent scaffold comprised of three zinc porphyrins, a boron-dipyrromethane (BODIPY) at one end and a free base porphyrin at the other end. ${ }^{[39]}$ To introduce selective energy input in our porphyrin scaffolds, a strapped zinc porphyrin bearing a BODIPY was incorporated into self-assembled triads (Figure 10). ${ }^{[40]}$ However, in static fluorescence quenching experiments,

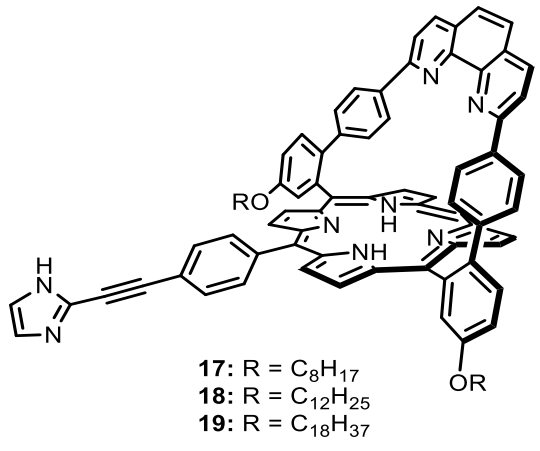

the estimated efficiency of the second energy transfer from the zinc porphyrin to the free base was still hampered by back energy transfer from the free base acceptor to the zinc porphyrin donor.

\subsection{The increasing role played by the surface}

The popularization of near field microscopy techniques such as atomic force microscopy (AFM) has led to the physical observation of nano-objects on surfaces and the development of scanning tunnelling microscopy (STM) has allowed the electronic characterization of nano-objects via the observation of frontier orbitals on surfaces. Both methods have significantly changed the classical approaches developed for self-assembly by introducing surface-molecule interactions as a new and powerful tool for the formation of organized self-assembly of molecules. In the field of nanomaterials, organization at the molecular level at the interface with a solid support is often still a challenge. Thus, the choice of the support for the observation of nanomaterials is a crucial parameter to take into account when designing the set of interactions that will lead to the formation of self-assemblies on surfaces.

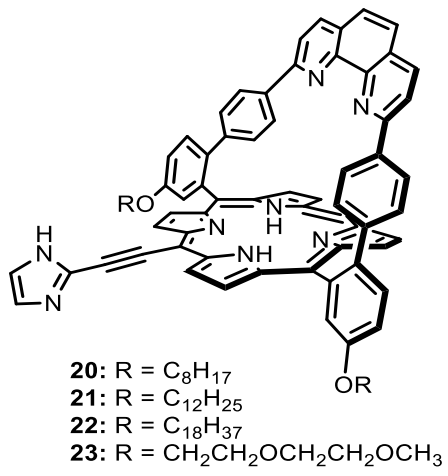


In the particular case of porphyrins deposited on metallic surfaces, the strength of surface-molecule interactions depends on the electronic coupling, in which case the surface's network and symmetry strongly influence the molecular organization. ${ }^{[32 c, 41,42]}$ Once deposited on a metallic surface, the reactivity of porphyrins can be utilized to form covalent assemblies of porphyrin wires along the axis of the lattice. ${ }^{[43]}$ On non-metallic surfaces, such as highly oriented pyrolytic graphite (HOPG), rather nonspecific hydrophobic interactions or aromatic stacking can be developed between the molecule and the solid substrate, in which case further organization requires additional interactions such as $\mathrm{CH}-\pi$ interactions between alkyl chains and the graphitic surface ${ }^{[44]}$ or the formation of iterative linear covalent bonds. ${ }^{[45]}$

\subsection{Unravelling surface induced assembly of porphyrin wires}

A major consequence of the surface's influence is that upon deposition on a surface, molecules capable of selfassembly can behave differently than in solution. This last section will show that, when carefully taken into account, molecule-surface interactions can be used and tuned to efficiently obtain highly organized, self-assembled nano-objects. For the first generation of iterative building blocks $17 Z n-19 Z n$ for self-assembled wires (Figure 11 ), ${ }^{1} \mathrm{H}$ NMR rapidly showed that the assembly process in solution was controlled by entropy to afford dimers formed by a head-to-tail association of two monomers [46] Deposition of these dimers of mica, where surface-molecule interactions were weak, led to aligned clusters of dimers; however, deposition on HOPG yielded objects with a totally different morphology that resulted from the assembly of monomers into islands. These results suggested that, due to the strong hydrophobic interaction of the porphyrin with the graphitic surface, the self-assembly process was confined in a 2D environment not adequate for dimerization.

To further understand the influences of the surface on the selfassembly process, building blocks $20 \mathrm{Zn}-22 \mathrm{Zn}$ were prepared, with the expectation that a shorter linker would create steric hindrance between the iterative units, thus perturbing the dimerization process. ${ }^{[47]}$ Broad spectra obtained from ${ }^{1} \mathrm{H}$ NMR solution studies of $20 \mathrm{Zn}-22 \mathrm{Zn}$ showed that, in non-coordinating
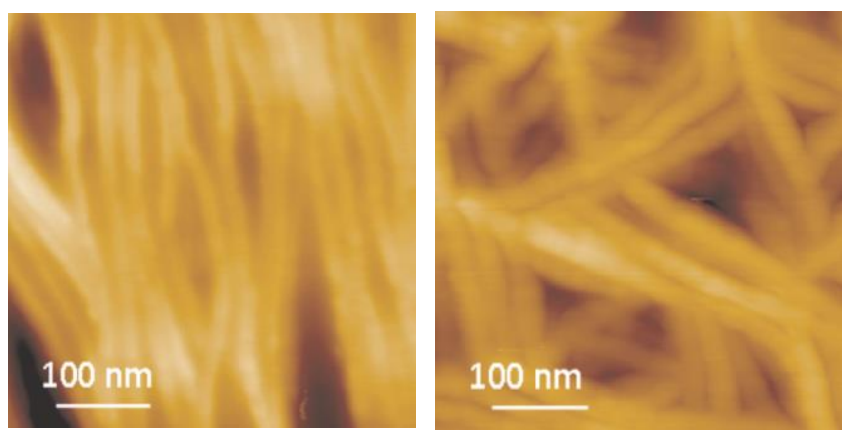

chlorinated solvents, ill-defined oligomeric species were in equilibrium with monomeric building blocks. Variable temperature experiments confirmed the dynamic and reversible character of the assemblies. On the contrary, the use of pyridine- $d_{5}$ afforded dimers as the only detectable species at NMR concentration at $25^{\circ} \mathrm{C}$, but heating the samples at $80{ }^{\circ} \mathrm{C}$ for 8 days yielded monomeric species only. Consequently, a systematic preparation of samples was implemented prior to deposition on surfaces. All building blocks were heated at $80^{\circ} \mathrm{C}$ in pyridine at millimolar concentrations for 8 days and the pyridine stock solution was diluted in a solvent of interest at micromolar concentrations of monomers for deposition on surfaces.

AFM studies of $17 Z n-19 Z n$ drop-cast on HOPG showed that the size of the objects formed increased when short alkyl chains were used because the chains were long enough to impose some directional organization on the surface, yet also short enough to provide a reasonable mobility of the building blocks in the film of solvent. ${ }^{[46]}$ This trend was confirmed with the shorter building blocks 20Zn-22Zn. Deposition of these building blocks, after dilution in $\mathrm{CH}_{2} \mathrm{Cl}_{2}$, afforded fibre-like structures reaching the micrometric length (Figure 12). ${ }^{[4]}$ These images provided information on the growth process due to the reminiscence of the hexagonal lattice in the case of $22 \mathrm{Zn}$ which bears long alkyl chains, and thus, develops much stronger interactions with the surface than 20Zn does. For 20Zn, which bears short alkyl chains, the lattice's influence on the orientation of the fibres is not present. Consequently, two final stages of the growth can be identified: one that takes place in the vicinity of the surface and a later step that occurs away from the surface and consists of growth in solution from seeding segments of fibers and free building blocks in solution.

These results and the lack of information on the initial steps of growth prompted the investigation of deposition in solvents that would modulate the interaction of the alkyl chains with the HOPG surface to slow down the growth process. Successful experiments were performed with dilute methylcyclohexane solutions prepared from pyridine solutions of building blocks. Slow evaporation of the solvent after dropcasting on HOPG yielded islands of aligned, single wires assembled from 22Zn (Figure 13). The wires form along the HOPG axis and are not interdigitated, despite the use of the longest alkyl side chain available. The islands can reach a few hundred nanometers in length, or the equivalent of a several hundred porphyrin building blocks. The height profile of the objects confirms their monolayer nature and provides a good estimation of the size of the wire that is missing (dark line in large island).

Figure 12. AFM topographic images of (left) $20 \mathrm{Zn}$ and (right) $22 \mathrm{Zn}$ after drop casting a $10 \mu \mathrm{M} \mathrm{CH}_{2} \mathrm{Cl}_{2}$ solution on $\mathrm{HOPG}$. 

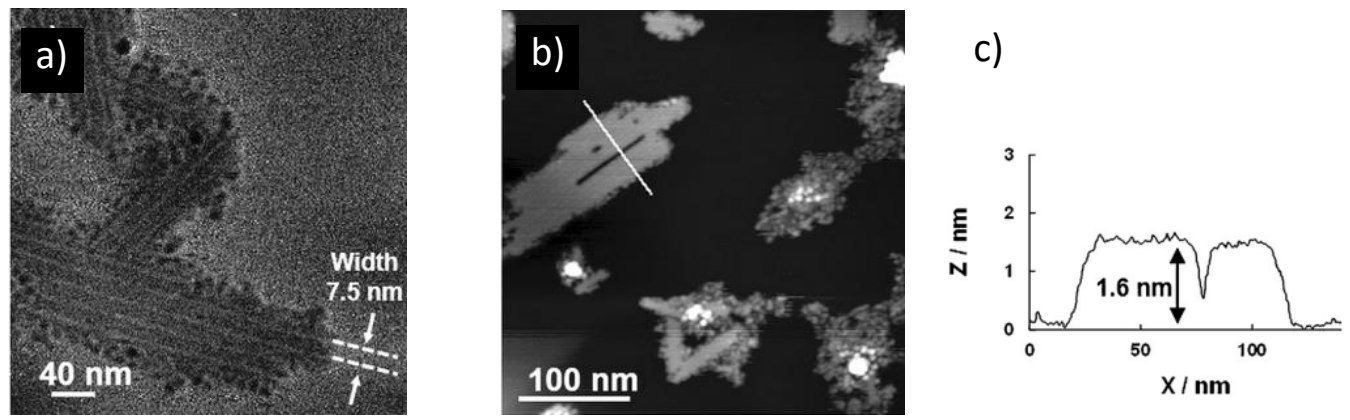

Figure 13. AFM images of islands of molecular wires formed by drop-casting $10 \mu \mathrm{M}$ solutions of $22 \mathrm{Zn}$ in methylcyclohexane onto HOPG.

Interestingly, if solvent evaporation is slowed down by placing the samples in a saturated atmosphere of methylcyclohexane, further events of the assembly process can be observed. Figure 14 shows a sample of object formed after a deposition time of 7 hours in methylcyclohexane. Whereas the linear arrangement of the wires is still present, the height profile shows the multi-layered character of the self-assembled nanoobject. Thus, the first island of wires serves as a template for the formation of successive layers of wires. These two steps are slow in methylcyclohexane due to the affinity of the solvent for the alkyl chains, ensuring the surface-directed deposition of the first layer and controlling the deposition of the next layers. This initial formation of seeds for the subsequent growth of bundles of

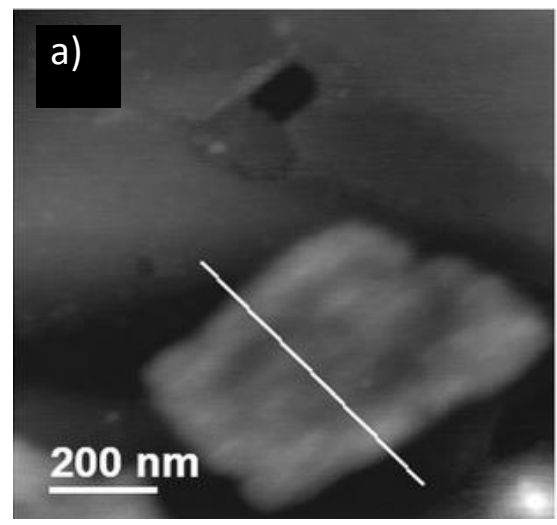

b)

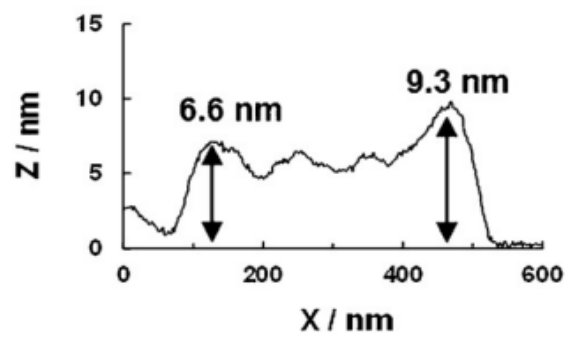

Figure 14. AFM images of a multilayered island of molecular wires formed by drop-casting a $10 \mu \mathrm{M}$ solution of $\mathbf{2 2 Z n}$ in methylcyclohexane onto HOPG with a 7 hour incubation in a methylcyclohexane saturated atmosphere. wires, similar to those depicted in Figure 12, is fast in $\mathrm{CH}_{2} \mathrm{Cl}_{2}$, which mainly controls the solubility of the porphyrin unit and promotes interdigitation of the alkyl chains due to poor interactions with these chains. These findings have shed new light on the growth process of fibres induced by surfaces, in the particular case of HOPG and studies with the hydrophilic building block $23 \mathrm{Zn}$ have shown that the surface assistance can be effective on mica. ${ }^{[48]}$

\section{Summary and Outlook}

This account shows that an initial quest for models of an enzymatic active site, namely cytochrome c oxidase, led to the design of a rather simple porphyrin derivative with a built-in distal pocket. The distant control on the axial binding inside this pocket conferred interesting properties to the model in mimicking the reduction of molecular oxygen and also led to unusual imidazole recognition via the $\mathrm{H}$-bond tuning of a simple axial coordination event. This peculiar feature turned the initial enzyme model into a building block for the self-assembly of photonic dyads and triads, and finally for the surface-induced self-assembly of molecular wires. Whereas Nature has many ways to illustrate the polyvalent character of the porphyrin structure, this account modestly illustrates the versatility of the phen-strapped porphyrin in two domains: hemoprotein modelling and the design of new nanomaterials. Hopefully, the synthetic availability will render the generic phen-strapped structure attractive for further developments in both fields. At this moment, inclusion of oxygen reduction catalysts in flexible electronics and combination of multiporphyrin light harvesting wires with carbon materials for photovoltaic applications are in progress.

\section{Acknowledgements}

JAW and JW are grateful to the CNRS and Universite de Strasbourg for funding of this work throughout the years. Specific support was obtained from the ANR via the collaborative project CHEMBLAST from 2006 to 2010 . CK is grateful to the JST-ANR Molecular technology program MECANO for a post-doctoral fellowship. We are also very 
thankful to all collaborators whose names can be found in the various literature references.

Keywords: Hemoprotein models • Strapped porphyrins • Inclusion complexes $\bullet$ Self-assembly $\bullet$ Molecular wires

[1] A. R. Battersby, Nat. Prod. Rep. 2000, 17, 507.

[2] A. Treibs, J. Lieb. Ann. Chem. 1935, 517, 172.

[3] G. W. Hodgson, B. L. Baker, Nature, 1964, 202, 125

[4] The original detailed study of oxygen binding on hemoglobin is 60 years old: a) L. Pauling, Proc. Nat. Acad. Sci. 1935, 21, 186; b) L. Pauling, C. D. Coryell, Proc. Nat. Acad. Sci. 1936, 22, 210.

[5] M. Paoli, R. Liddington, J. Tame, A. Wilkinson, G. Dodson, J. Mol. Biol. 1996, 256, 775.

[6] J. Chiefari, K. Griebenow, N. Griebenow, T. S. Balaban, A. R. Holzwarth, K. Schaffner, J. Phys. Chem. 1995, 99, 1357.

[7] R. J. Cogdell, N. W Isaacs, A. A Freer, T. D. Howard, A. T Gardiner, S. M. Prince, M. Z. Papiz, FEBS Lett. 2003, 555, 35.

[8] J. P. Collman, R. R. Gagne, C. A. Reed, T. R. Halbert, G. Lang, W. T. Robinson, J. Am Chem. Soc. 1975, 97, 1427; J. P. Collman, S. E. Groh J. Am Chem. Soc. 1982, 104, 1391 and references cited.

[9] a) A. R. Battersby, A. D. Hamilton, J. Chem. Soc. Chem. Commun. 1980, 117 and references cited; b) J. E. Baldwin, T. Klose, M. Peters, J. Chem. Soc. Chem. Commun. 1976, 881.

[10] J. E. Baldwin, M. J. Crossley, T. Klox, E. A. O'Rear III, M. Peters, Tetrahedron 1982, 38, 27.

[11] T. G. Traylor, Acc. Chem. Res. 1981, 14, 102

[12] D. Lexa, M. Momenteau, P. Rentien, G. Rytz, J. M. Savéant, F. Xu, J. Am. Chem. Soc. 1984, 106, 4755 and references cited.

[13] a) J. P. Collman, L. Fu, P. C. Herrmann, X. Zhang, Science 1997, 275 , 949; b) J. P. Collman, L. Fu, P. C. Herrmann, Z. Whang, M. Rapta, M. Bröring, R. Schwenninger, B. Boitrel, Angew. Chem. Int. Ed. 1998, 37, 3397 ; c) D. Ricard, B. Andrioletti, M. L'Her, B. Boitrel, Chem. Commun. 1999, 1523.

[14] R. A. Scott, Ann. Rev. Biophys. Biophys. Chem. 1989, 18, 137.

[15] a) J. P. Collman, R.n Boulatov, C. J. Sunderland, L.i Fu Chem. Rev., 2004, 104, 561; b) S. Ferguson-Miller, G. T. Babcock, Chem. Rev. 1996, 96, 2889; c)T. Tsukihara, H. Aoyama, E. Yamashita, T. Tomizaki, H. Yamaguchi, K. Shinzawa-Itoh, R. Nakashima, R. Yaono, S. Yoshikawa, Science, 1995, 269, 1069.

[16] J. S. Manka, D. S. Lawrence, Tetrahedron Lett. 1989, 30, 6989

[17] a) S. Chardon-Noblat, J.-P. Sauvage, Tetrahedron, 1991, 47, 5123; b) C. Dietrich-Buchecker, B. Colasson, M. Fujita, A. Hori, N. Geum, S. Sakamoto, K. Yamaguchi, J.-P. Sauvage, J. Am. Chem. Soc. 2003, 125, 5717.

[18] These porphyrins are consistently prepared in 60-70\% yields although we reported lower yields in references Erreur ! Signet non défini. and 20.

[19] J. A. Wytko, E. Graf,; J. Weiss, J. Org. Chem. 1992, 57, 1015.

[20] M. Koepf, F. Melin, J. Jaillard, J. Weiss, Tetrahedron Lett. 2005, 46, 139.

[21] P. Ochsenbein, M. Bonin, K. Schenk, J. Froidevaux, J. Wytko, E. Graf, J. Weiss, J. Eur. Inorg. Chem. 1999, 7, 1175.

[22] F. Melin, C. Boudon, M. Lo, K. J. Schenk, M. Bonin, P. Ochsenbein, M. Gross, J. Weiss, J. Porph. Phthalocyanines, 2007, 11, 212.

[23] M. Lo, D. Mahajan, J. A. Wytko, C. Boudon, J. Weiss, Org. Lett., 2009, 11, 2487.

[24] F. Melin, S. Choua, M. Bernard, P. Turek, J. Weiss, Inorg. Chem. 2006, 45, 10750.

[25] P. Vorburger, J. A. Wytko, J. Weiss, J. Porph. Phthalocyanines 2014, 18,804 .
[26] F. Melin, A. Trivella, M. Lo, C. Ruzié, I. Hijazi, N. Oueslati, J.A. Wytko, B. Boitrel, C. Boudon, P. Hellwig, J. Weiss, J. Inorg. Biochem. 2012 108, 196.

[27] P. Vorburger, P. Hellwig, F. Melin, J. Wytko, C. Boudon, J. Weiss unpublished results.

[28] a) For reviews see: H. Ogoshi, T. Mizutani, T. Hayashi, Y. Kuroda, in "The Porphyrin Handbook" K. M.Kadish, K. M.Smith, R. Guilard Eds. Acad. Press: New York, 2000; Vol. 6, p. 279; b) J. Weiss J. Incl. Phenom. 2001, 40, 1.

[29] J. Froidevaux, P. Ochsenbein, M. Bonin, K. Schenk, P. Maltese, J. P. Gisselbrecht, J. Weiss J. Am. Chem. Soc. 1997, 119, 12362.

[30] D. Paul, F. Melin, C. Hirtz, J. Wytko, P. Ochsenbein, M. Bonin, K Schenk, P. Maltese, J. Weiss Inorg. Chem. 2003, 42, 3779

[31] a) J. Brandel, A. Trabolsi, F. Melin, M. Elhabiri, J. Weiss, Inorg. Chem. 2007, 46, 9534; b) J. Brandel, A.Trabolsi, H. Traboulsi, F. Melin, M. Koepf, J. Wytko, M. Elhabiri, J. Weiss, A.-M. Albrecht-Gary, Inorg. Chem. 2009, 48, 3743

[32] For selected reviews see: a) ) J.-C. Chambron, V. Heitz, J.-P. Sauvage In The Porphyrin Handbook, K. M. Kadish, K. M. Smith, R. Guilard, Eds Academic Press: San Diego, 2000, Vol. 6, 1-42; b) I. Beletskaya, W. S. Tyurin, A. Y. Tsivadze, R. Guilard, C. Stern, Chem. Rev. 2009, 109, 1659; c) M. Koepf, J. Weiss, F. Cherioux, J. A. Wytko, Coord. Chem. Rev. 2012, 256, 2872; d) C. Zhang, P. Chen, H. Dong, Y. zhen, M. Liu, W. Hu, Adv. Mater. 2015, 36, 5379

[33] J. L. Sessler, B. Wang, A. Harriman, J. Am. Chem. Soc. 1995, 117, 704

[34] R. A. Haycock, C. A. Hunter, D. A. James, U. Michelsen, L. R. Sutton, Org. Lett. 2000, 2, 2435.

[35] K. Ogawa, Y. Kobuke, Angew. Chem. Int. Ed. 2000, 39, 4070.

[36] M. Abdelhameed, A. Langlois, P.L. Karsenti, S. Richeter, R. Ruppert, P D. Harvey, Chem. Commun. 2014, 50, 14609

[37] D. Paul, J. A. Wytko, M. Koepf, J. Weiss, Inorg. Chem. 2002, 41, 3699.

[38] I. Leray, D. Paul, E. Regnier, M. Koepf, J. A. Wytko, C. Boudon, J. Weiss, Photochem. Photobio. Sci. 2005, 280.

[39] R. Wagner, J. S. Lindsey, J. Am. Chem. Soc. 1994, 116, 9759.

[40] M. Koepf, A. Trabolsi, M. Elhabiri, J. A. Wytko, D. Paul, A. M. AlbrechtGary, J. Weiss, Org. Lett. 2005, 1279.

[41] L. Zhang, M. Lepper, M. Stark, R. Schuster, D. Lungerich, N. Jux, H.-P. Steinrìck, H. Marbach Chem. Eur. J. 2016, 22, 3347.

[42] M. El Garah, Y. Makoudi, F. Palmino, E. Duverger, P. Sonnet, L. Chaput, A. Gourdon, F. Cherioux, ChemPhysChem, 2009, 10, 3190.

[43] a) S. Haq, F. Hanke, M. S. Dyer, M. Persson, P. lavicoli, D. Amabilino, R. Raval, J. Am. Chem. Soc. 2011, 133, 12031. b) S. Haq, F. Hanke, J. Sharp, M. Persson, D. B. Amabilino, R. Raval, ACS Nano, 2014, 8 8856; c) H. Zhang, H. Lin, K. Sun, L. Chen, Y. Zagranyarski, N. Aghdassi, S. Duhm, Q. Li, D. Zhong, Y. Li, K. Mullen, H. Fuchs, L. Chi, J. Am. Chem. Soc. 2015, 137, 4022.

[44] a) Groszek, A. J. Proc.R. Soc. Lond. A 1970, 314, 473; b) Venkataraman, B.; Breen, J. J.; Flynn, G. W. J. Phys. Chem. 1995, 99, 6608; c) Qiu, X.; Wang, C.; Yin, S.; Zeng, Q.; Xu, B.; Bai, C. J. Phys. Chem. B. 2000, 104, 3570.

[45] a) L. Grill, M. Dyer, L. Lafferentz, M. Persson, M. V. Peters, Nature Nanotech. 2007, 2, 687.

[46] M. Koepf, J. A. Wytko, J.-P. Bucher, J. Weiss, J. Am. Chem. Soc. 2008 $130,9994$.

[47] V. Rauch, J. A. Wytko, M. Takahashi, Y. Kikkawa, M. Kanesato, J. Weiss, Org. Lett. 2012, 14, 1998.

[48] V. Rauch, Y. Kikkawa, M. Koepf, I. Hijazi, J. A. Wytko, S. Campidelli, A Goujon, M. Kanesato, J. Weiss Chem. Eur. J. 2015, 21, 13437. 
